\title{
A Family of Activity-Dependent Neuronal Cell-Surface Chondroitin Sulfate Proteoglycans in Cat Visual Cortex
}

\author{
Cynthia Lander, Peter Kind, Michael Maleski, and Susan Hockfield \\ Section of Neurobiology, Yale University School of Medicine, New Haven, Connecticut 06520-8001
}

Monoclonal antibody Cat-301 recognizes a chondroitin sulfate proteoglycan (CSPG) expressed on the extracellular surface of cell bodies and proximal dendrites of specific subsets of neurons in many areas of the mammalian CNS, including the cat visual cortex. The Cat-301 CSPG is first detected at the close of the critical period in development, a period during which the pattern of neuronal activity determines the mature synaptic circuitry and neuronal phenotype. In the cat visual cortex, dark-rearing from birth prolongs the duration of the critical period and attenuates the expression of the Cat-301 antigen, implicating the Cat-301 CSPG in the cellular mechanisms that terminate the period of synaptic plasticity. Because the Cat301 antigen is expressed on only a limited subset of neurons, we have further examined the molecular heterogeneity among neuronal cell-surface CSPGs and have asked (1) whether other neuronal subsets carry distinct CSPGs and (2) whether the activity-dependent expression of the Cat-301 CSPG is a property generalizable to related cell-surface CSPGs. Here, we report two new monoclonal antibodies, Cat-315 and Cat-316, which together with Cat-301 define a family of at least seven related yet distinct CSPGs. These three antibodies define nonidentical subsets of neurons in the cat visual cortex. The expression of normal levels of these CSPGs is reduced by darkrearing. Together, these data show that the family of cellsurface CSPGs is molecularly diverse, that different sets of neurons express distinct complements of cell-surface antigens, and that the regulation of CSPG expression by activity may be a general feature of neuronal cell-surface CSPGs.

Key words: neuronal subsets; perineuronal nets; Cat-301; extracellular matrix; CNS; dark-rearing
Proteoglycans, glycoproteins decorated with linear polymers of repeating disaccharides called glycosaminoglycans, are constituents of the extracellular matrix of many non-neural tissues (Wight et al., 1991). We and others have demonstrated that chondroitin sulfate proteoglycans (CSPGs) are also found in the adult mammalian CNS, in association with neuronal cell surfaces in a manner reminiscent of the perineuronal nets first described by Golgi (1893) and Ramon y Cajal (1897) (for review, see Celio and Blumcke, 1994). The perineuronal nets, then, may represent the neuronal extracellular matrix.

CSPGs are molecularly heterogeneous, varying in the composition of both the protein core and the carbohydrate side chains. Different neuronal subsets have different complements of CSPGs in their perineuronal nets (Celio and Blumcke, 1994), so that perineuronal CSPGs could regulate the extracellular milieu of neurons in cell type-specific ways. Several neuronal cell-surface CSPGs are first expressed relatively late in development, at the end of the period of synaptic plasticity, leading to the suggestion that the elaboration of the mature extracellular matrix may be an important element in limiting synaptic plasticity (Hockfield et al., 1990).

We described previously a cell-surface CSPG recognized by monoclonal antibody Cat-301, which is expressed on the cell bodies and proximal dendrites of specific subsets of neurons in many areas of the mammalian CNS, including the visual cortex of

Received July 2, 1996; revised Dec. 23, 1996; accepted Dec. 31, 1996.

This work was supported by National Institutes of Health Grant EY06511. We wish to thank Gail Kelly for invaluable technical assistance, Drs. Anders Aspberg, Peter Braun, and Yu Yamaguchi for advice on TFMS deglycosylation, and Drs. Hong Zhang and Jane Minturn for critical reading of this manuscript.

Correspondence should be addressed to Cynthia Lander, Section of Neurobiology, Yale University, 333 Cedar Street, SHM C-405, New Haven, CT 06520-8001.

Copyright (C) 1997 Society for Neuroscience $0270-6474 / 97 / 171928-12 \$ 05.00 / 0$ cats and primates (Hockfield et al., 1983, 1990; DeYoe et al., 1990). The Cat-301 CSPG is normally expressed at the end of the critical period in development during which neuronal activity can influence synaptic connectivity and neuronal phenotype. Darkrearing from birth, which extends the duration of the critical period in the cat visual cortex, inhibits the expression of the Cat-301 CSPG, consistent with the possibility that this CSPG could play a role limiting synaptic plasticity (Guimaraes et al., 1990; Hockfield et al., 1990).

In view of the apparent heterogeneity among cell-surface CSPGs and the fact that Cat-301 labels only a restricted subset of neurons, the goals of the present study were, first, to begin to explore the degree of heterogeneity within this family of molecules and, second, to determine whether the activity-dependent expression of the Cat-301 CSPG is a property unique to the Cat-301 CSPG or, instead, a property shared by other cell-surface CSPGs. Toward this end, we have generated several new antibodies to brain CSPGs. We report two of these here: Cat-315 and Cat-316, which recognize cell-surface antigens of the same apparent molecular weight as Cat-301. We show that these antibodies, together with Cat-301, define a family of nonidentical cell-surface CSPGs expressed on distinct subsets of neurons. Our biochemical analyses demonstrate that the population of brain CSPGs is likely to be extremely complex. Furthermore, these new reagents demonstrate that the expression of normal levels of several members of this family of cell-surface CSPGs in the cat visual cortex requires normal visual activity. Together, these data suggest (1) that this family of molecules may be even more heterogeneous than previously appreciated and (2) that activity-dependent expression may be a general feature for neuronal cell-surface CSPGs. 


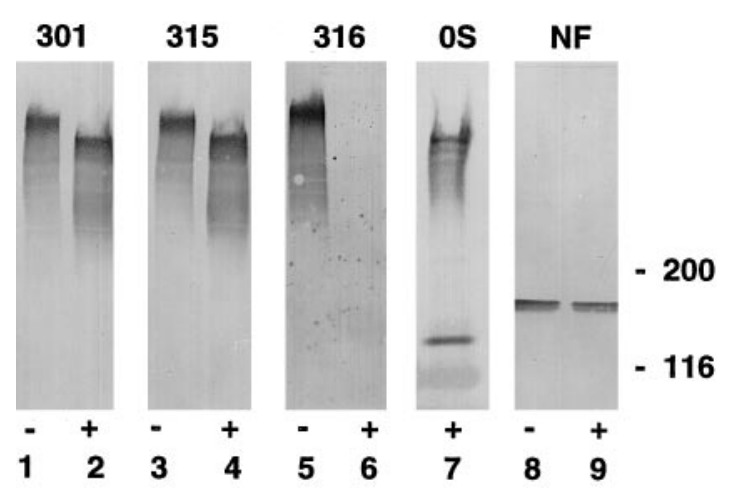

Figure 1. Monoclonal antibodies Cat-301, Cat-315, and Cat-316 recognize high molecular weight CSPGs. Guanidine extracts of cat visual cortex were incubated with $(+)$ (lanes $2,4,6$, and 9) or without $(-)$ (lanes 1, 3, 5, and 8) bovine testicular hyaluronidase (which has chondroitinase activity). In lane 7, Cat-316 immunoprecipitated cat visual cortex extract was digested with bovine testicular hyaluronidase All samples were Western-blotted and probed with the following antibodies: lanes 1 and 2, Cat-301; lanes 3 and 4, Cat-315; lanes 5 and 6 , Cat-316; lane 7, anti-0S; lanes 8 and 9, anti-neurofilament $160 \mathrm{kDa}$. Removal of chondroitin sulfate produces a shift in the molecular weight of the antigens recognized by Cat-301 and Cat-315, indicating that these antibodies recognize CSPGs. Cat-316 immunoreactivity disappears after digestion, indicating that the Cat-316 epitope is likely to be chondroitin sulfate. In lane 7, a Cat-316 immunoprecipitate digested with enzyme is immunoreactive for anti-0S, confirming that Cat-316 recognizes a CSPG. A duplicate blot stained with secondary antibody alone indicates that the band of $\sim 116 \mathrm{kDa}$ in lane 7 represents immunoglobulin (not shown). Lack of shift in mobility of the neurofilament antigen indicates that the shift in molecular weight seen in lanes $1-7$ is attributable specifically to the removal of chondroitin sulfate glycosaminoglycans rather than to nonspecific protease activity. Identical results were obtained after digestion with either bovine testicular hyaluronidase or chondroitinase ABC. (For additional information about this and related work, see the Hockfield Web Site: http://info.med.yale.edu/neurobio/hockfield/hockfield.html.)

\section{MATERIALS AND METHODS}

Antibody generation. Brain proteoglycans were partially purified by two successive dissociative cesium chloride $(\mathrm{CsCl})$ density gradients. Cat brains (PelFreez Biologicals, Rogers, AK) were homogenized in a $1 \mathrm{~mm}$

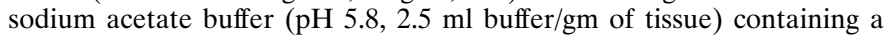
cocktail of protease inhibitors $(2 \mathrm{mM}$ EDTA; $5 \mu \mathrm{g} / \mathrm{ml}$ leupeptin, $5 \mathrm{~mm}$ E-aminocaproic acid, and $5 \mathrm{~mm} \mathrm{~N}$-ethylmaleamide dissolved in $5 \mathrm{~mm}$ sodium phosphate buffer; $1 \mathrm{~mm}$ phenylmethylsulfonyl fluoride and 5 $\mu \mathrm{g} / \mathrm{ml}$ leupeptin dissolved in dimethylsulfoxide). This material was rehomogenized in an equal volume of $8 \mathrm{M}$ guanidine hydrochloride and stirred for $2 \mathrm{hr}$ at $4^{\circ} \mathrm{C}$. CsCl was added to an initial density of $1.38 \mathrm{gm} / \mathrm{ml}$, and the extract was centrifuged for $30 \mathrm{~min}$ at $47,000 \times g$ to remove lipids. The remaining material was centrifuged for $72 \mathrm{hr}$ at $200,000 \times g$, and fractions of increasing buoyant density were harvested by pipetting from the top of the gradient. Each fraction was dialyzed overnight against TBS $(50 \mathrm{mM}$ Tris, $150 \mathrm{~mm} \mathrm{NaCl}, \mathrm{pH} 7.4$ ) and concentrated in an Amicon ultrafiltration unit with a PM-30 membrane.

Aliquots of each fraction were digested with chondroitinase $\mathrm{ABC}$ (ICN, Aurora, OH), as described below, and assayed for Cat-304 (Guimaraes et al., 1990), antibodies to the unsulfated, 4-sulfated, or 6-sulfated disaccharides of CSPGs that are exposed after chondroitinase digestion (anti-0S, anti-4S, and anti-6S; "stub antibodies;" ICN), neurofilament 160 $\mathrm{kDa}$ (Boehringer Mannheim, Indianapolis, IN), and glial fibrillary acidic protein (GFAP) (Sigma, St. Louis, MO) immunoreactivity by Western blot and/or dot blot analyses. Some proteoglycan-containing fractions also contained a significant amount of immunoreactivity for neurofilament and GFAP. These fractions were subjected to a second dissociative $\mathrm{CsCl}$ gradient (as above). Ten fractions were collected, dialyzed against TBS, and assayed for Cat-304, stub, and intermediate filament immunoreactivity. Those fractions positive for Cat-304 and stubs but negative for GFAP and neurofilament were pooled and concentrated by ethanol precipitation as follows. Dextran sulfate $(0.001 \mathrm{mg} / \mathrm{ml})$ was added to the sample as a bulk precipitator, followed by 3 vol of $95 \%$ ethanol $/ 0.13 \%$ potassium acetate. This mixture was frozen overnight at $20^{\circ} \mathrm{C}$, and the precipitate was pelleted at $27,000 \times g$ at $0^{\circ} \mathrm{C}$ for $30 \mathrm{~min}$, resuspended in $1 \mathrm{ml}$ of the ethanol mixture, and pelleted again under identical conditions.

Resulting precipitates were resuspended in TBS, emulsified 1:1 in Freund's complete adjuvant (Life Technologies, Grand Island, New York), and used to immunize Balb/c mice by injection into the hind footpads on days $1,5,9$, and 13 . On day 14 , mice were killed by cervical dislocation, and the popliteal and inguinal nodal lymphocytes were collected, fused with NS-1 myeloma cells, suspended in selection medium, and plated onto macrophage feeder layers (Hockfield et al., 1993). Hybridoma supernatants were screened on Western blots of cat brain homogenate. Those supernatants that showed immunoreactivity to high molecular weight proteins were subsequently assayed by immunohistochemistry on sections of cat visual cortex. Hybridoma lines showing reactivity with neuronal cell surfaces were stabilized by three rounds of subcloning by limiting dilution.

Deglycosylation. Enzymes for deglycosylation were as follows: chondroitinase ABC $(0.25 \mathrm{U} / \mathrm{ml}$; ICN), bovine testicular hyaluronidase (Wydase, $75 \mathrm{U} / \mathrm{ml}$; Wyeth-Ayerst, Philadelphia, PA), and $N$-glycosidase F (200 U/ml; Boehringer Mannheim). For each, samples were incubated overnight at $37^{\circ} \mathrm{C}$ in the presence of enzyme and protease inhibitors and analyzed by Western blotting. For $N$-glycosidase F digestion, samples, $\mathrm{pH}$ 8.6 , were first denatured by boiling in $0.5 \%$ SDS and $50 \mathrm{~mm}$
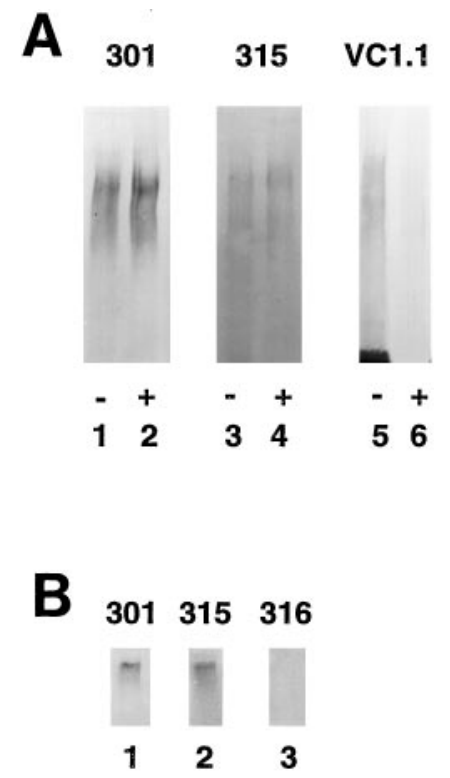

Figure 2. Monoclonal antibodies Cat-301 and Cat-315 are likely to recognize epitopes present on the protein core and not the carbohydrate moieties of CSPGs. $A$, The epitopes recognized by Cat-301 and Cat-315 are not $\mathrm{N}$-linked carbohydrates. Cat brain homogenates were incubated in the presence $(+)$ (lanes 2,4 , and 6 ) or absence $(-)$ (lanes 1, 3, and 5) of $\mathrm{N}$-glycosidase F. All samples were Western-blotted and probed with the following antibodies: lanes 1 and 2, Cat-301; lanes 3 and 4, Cat-315; lanes 5 and 6 , VC1.1. Incubation with $\mathrm{N}$-glycosidase $\mathrm{F}$ produces no change in Cat-301 or Cat-315 immunoreactivity but eliminates immunoreactivity for VC1.1 (an N-linked carbohydrate epitope), indicating that digestion with $\mathrm{N}$-glycosidase $\mathrm{F}$ was complete and also that Cat-301 and Cat-315 do not recognize $\mathrm{N}$-linked carbohydrate epitopes. $B$, The epitopes recognized by Cat-301 and Cat-315 are not likely to be O-linked carbohydrates. Cat brain homogenates were chemically deglycosylated with TFMS and then Western-blotted and probed with the following antibodies: lane 1, Cat301; lane 2, Cat-315; lane 3, Cat-316. Incubation with TFMS abolishes Cat-316 (an O-linked carbohydrate epitope) immunoreactivity, whereas immunoreactivity for both Cat-301 and Cat-315 is retained. Chemical deglycosylation also produces a sharpening of the bands recognized by Cat-301 and Cat-315. Each lane was loaded with a preparation that contained $70 \mu \mathrm{g}$ of protein before TFMS treatment. (For comparison see Fig. 1, lanes $1-6$, each of which was loaded with a preparation that contained $25 \mu \mathrm{g}$ of protein before digestion.) 
A

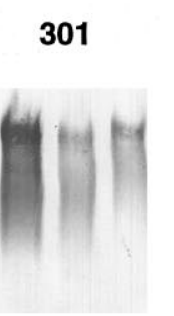

315

316

B

$301 \quad 315$

A B C
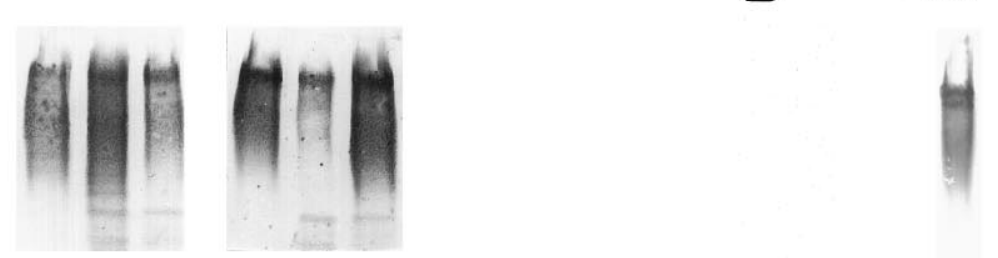

123

A 1 B 1 C

$\begin{array}{lll}\text { A } & \text { B } & \text { C } \\ 7 & 8 & 9\end{array}$

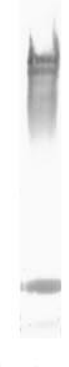

1

C

315

315

316

D $\quad 301$

$315 \quad 316$
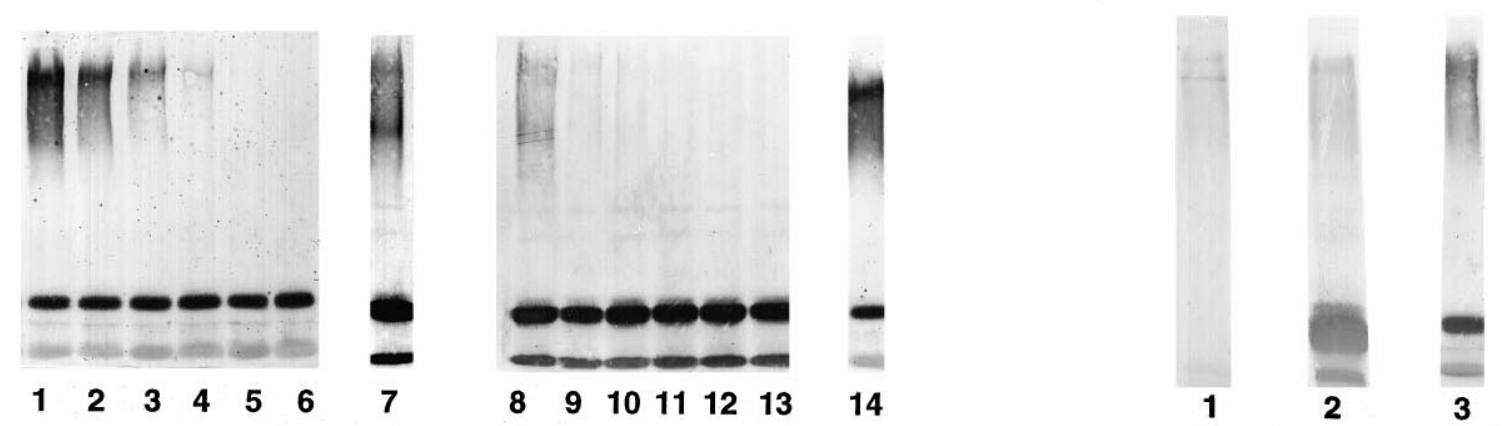

E

(A)

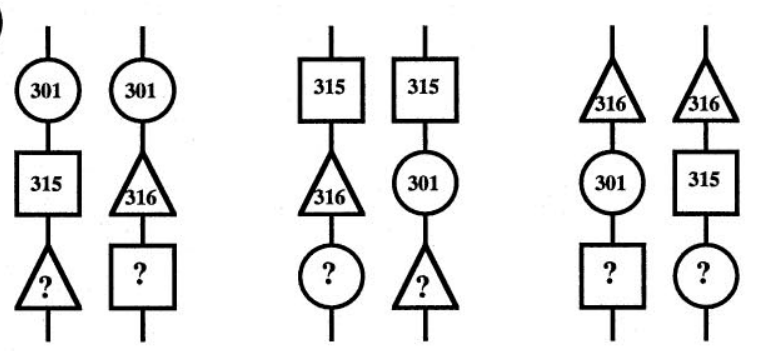

(B)

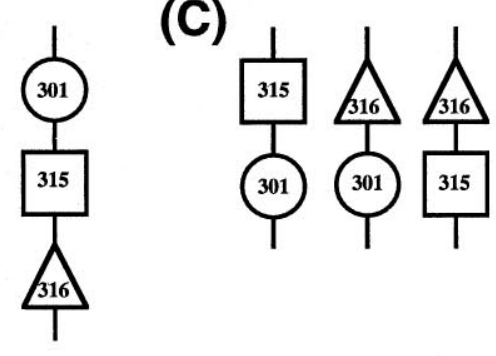

(D)

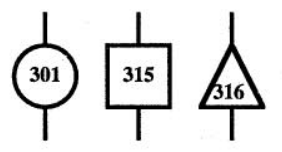



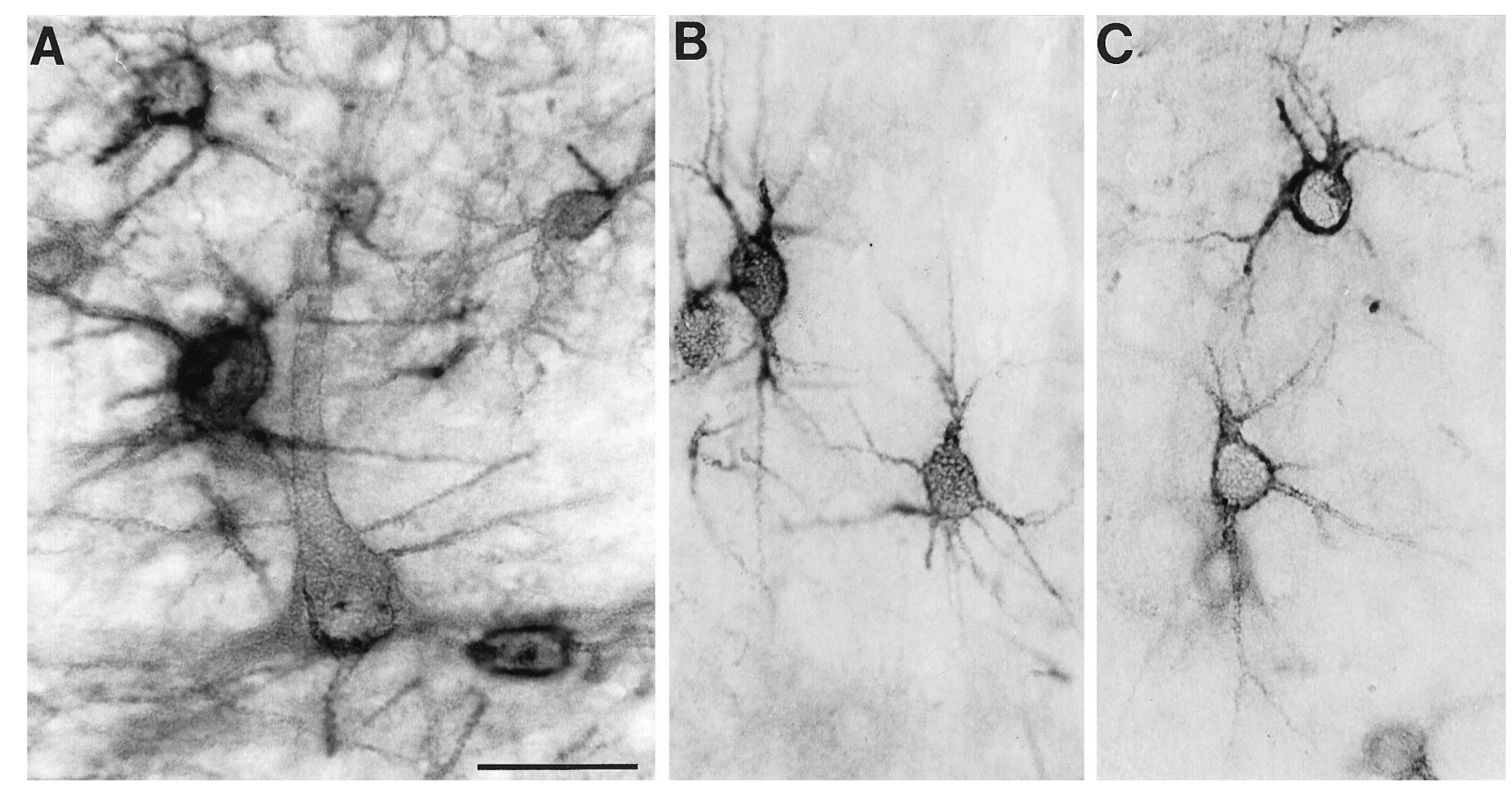

Figure 4. Cat-301, Cat-315, and Cat-316 immunoreactivity is distributed in a lattice-like pattern over the surfaces of neurons. Cat-301, Cat-315, and Cat-316 immunoreactivity is associated with the surface of neuronal cell bodies and proximal dendrites in the cat primary visual cortex. Staining is not uniform over the cell surface but is interrupted by unstained holes or fenestrae. Cat-301 $(A)$ immunoreactivity forms a perineuronal net surrounding a layer 5 pyramidal neuron. The lattice-like staining with Cat-315 $(B)$ and Cat-316 $(C)$ shown here is associated with nonpyramidal neurons in layer $2 / 3$. Nonpyramidal neurons are labeled by all three antibodies; pyramidal neurons are labeled only by Cat-301 and Cat-316. Scale bar, $50 \mu \mathrm{m}$.

$\beta$-mercaptoethanol, and $5 \mu \mathrm{l}$ of $7.5 \%$ Nonidet P-40 was added during enzyme incubation. Efficacy of chondroitinase $\mathrm{ABC}$ and bovine testicular hyaluronidase digestions was confirmed by a shift in mobility of the Cat-301 antigen, as well as exposure of the "stub" epitopes (described above). Efficacy of $N$-glycosidase F digestion was confirmed by the complete elimination of immunoreactivity for $\mathrm{VC1} 1$, an antibody that recognizes the N-linked HNK-1 carbohydrate epitope found on various neural glycoproteins (Naegele and Barnstable, 1991).

For chemical deglycosylation, samples were concentrated by trichloro- acetic acid (TCA) precipitation and deglycosylated, as detailed in Horvath et al. (1989). Briefly, the TCA precipitate was washed with ether/ ethanol (1:1), dried, and then dissolved in $5 \mu$ l anisole (Sigma) and incubated with $45 \mu \mathrm{l}$ trifluoromethanesulfonic acid (TFMS, Sigma) on ice under nitrogen for a range of time intervals. Digestion was terminated by incubation with a mixture of ice-cold ether $(800 \mu \mathrm{l})$ and pyridine $(100 \mu \mathrm{l})$ (Sigma) on dry ice for $1 \mathrm{hr}$. Samples were centrifuged, the supernatant was discarded, and the pellet was again dried. The pellet was dissolved in $800 \mu \mathrm{l} 1 \%$ Triton X-100, and then $120 \mu \mathrm{l}$ TCA was added; this mixture $\leftarrow$

Figure 3. Monoclonal antibodies Cat-301, Cat-315, and Cat-316 recognize distinct but overlapping sets of CSPGs. $A$, CSPGs recognized by each of the three antibodies also carry epitopes for the other two antibodies. Guanidine extracts of cat visual cortex were immunoprecipitated with Cat-301 $(A)$, Cat-315 (B), or Cat-316 (C). The immunoprecipitated antigens were eluted from the beads and Western-blotted with Cat-301 (lanes 1-3), Cat-315 (lanes 4-6), or Cat-316 (lanes 7-9). Each immunoprecipitate is recognized by both of the other two antibodies as well as by the precipitating antibody, indicating that Cat-301, Cat-315, and Cat-316 recognize CSPGs with shared epitopes. B, There are brain CSPGs that carry epitopes for all three antibodies. A Cat-316 immunoprecipitate was digested with chondroitinase ABC. The resulting material was immunoprecipitated with Cat-301 and then Westernblotted with Cat-301 (lane 1) and Cat-315 (lane 2), demonstrating the existence of CSPGs that possess epitopes recognized by all three antibodies. $C$, Each antibody also recognizes CSPGs that do not carry epitopes for all three antibodies. Guanidine extracts of cat visual cortex were subjected to six successive rounds of immunoprecipitation with Cat-316-coupled immunobeads (lanes 1-6). After immunodepletion with Cat-316, the extract was immunoprecipitated with Cat-315 (lane 7). The antigens were eluted from the beads and then Western-blotted with Cat-316 (lanes 1-6) and Cat-315 (lane 7). After immunodepletion with Cat-316, the extract still shows substantial amounts of Cat-315 immunoreactivity, indicating the presence of Cat-315 antigens that do not possess the Cat-316 epitope. The reciprocal experiment, in which the extract was first depleted of Cat-315 (lanes 8-13, probed with Cat-315) and then immunoprecipitated with Cat-316 (lane 14, probed with Cat-316), similarly reveals a population of Cat-316 antigens that is not recognized by Cat-315. In each case, the final immunoprecipitate also showed immunoreactivity for the third antibody (data not shown). Together, these depletion experiments reveal Cat-315+/Cat-301+, Cat-316+/Cat-301+, and Cat-316+/Cat-315+ populations of proteoglycans [see Fig. 3E, (C)]. D, There are brain CSPGs that carry only one of the three epitopes. Guanidine extracts of cat visual cortex were subjected to six successive rounds of immunoprecipitation with Cat-316, followed by six rounds of immunoprecipitation with Cat-315. The remaining Cat-316- and Cat-315-depleted material was immunoprecipitated with Cat-301-coupled immunobeads and then Western-blotted with Cat-301 (lane 1) to demonstrate the presence of antigens that possess only Cat-301 but not Cat-315 or Cat-316 epitopes. Identical analyses were performed for Cat-315 (lane 2) and Cat-316 (lane 3). Together, these double-depletion experiments reveal CSPG populations that possess only one of the three epitopes identified by Cat-301, Cat-315, or Cat-316. E, Schematic representation of the classes of CSPGs revealed by the biochemical analyses performed here. $A$, The co-precipitation analysis shows that CSPGs can carry epitopes for at least two of the three antibodies but does not address the presence of an epitope for the third antibody. $B$, Carrying the co-precipitation analysis to the third antibody reveals the presence of CSPGs with epitopes for all three antibodies. $C$, The immunodepletion analyses show that not all CSPGs carry epitopes for all three antibodies, but that there are CSPGs that carry epitopes for any pair of antibodies but do not carry epitopes for the third antibody. $D$, Three-part immunodepletions show that there are CSPGs that carry epitopes for only one of the three antibodies. Together, this analysis identifies seven immunologically distinct CSPGs. 


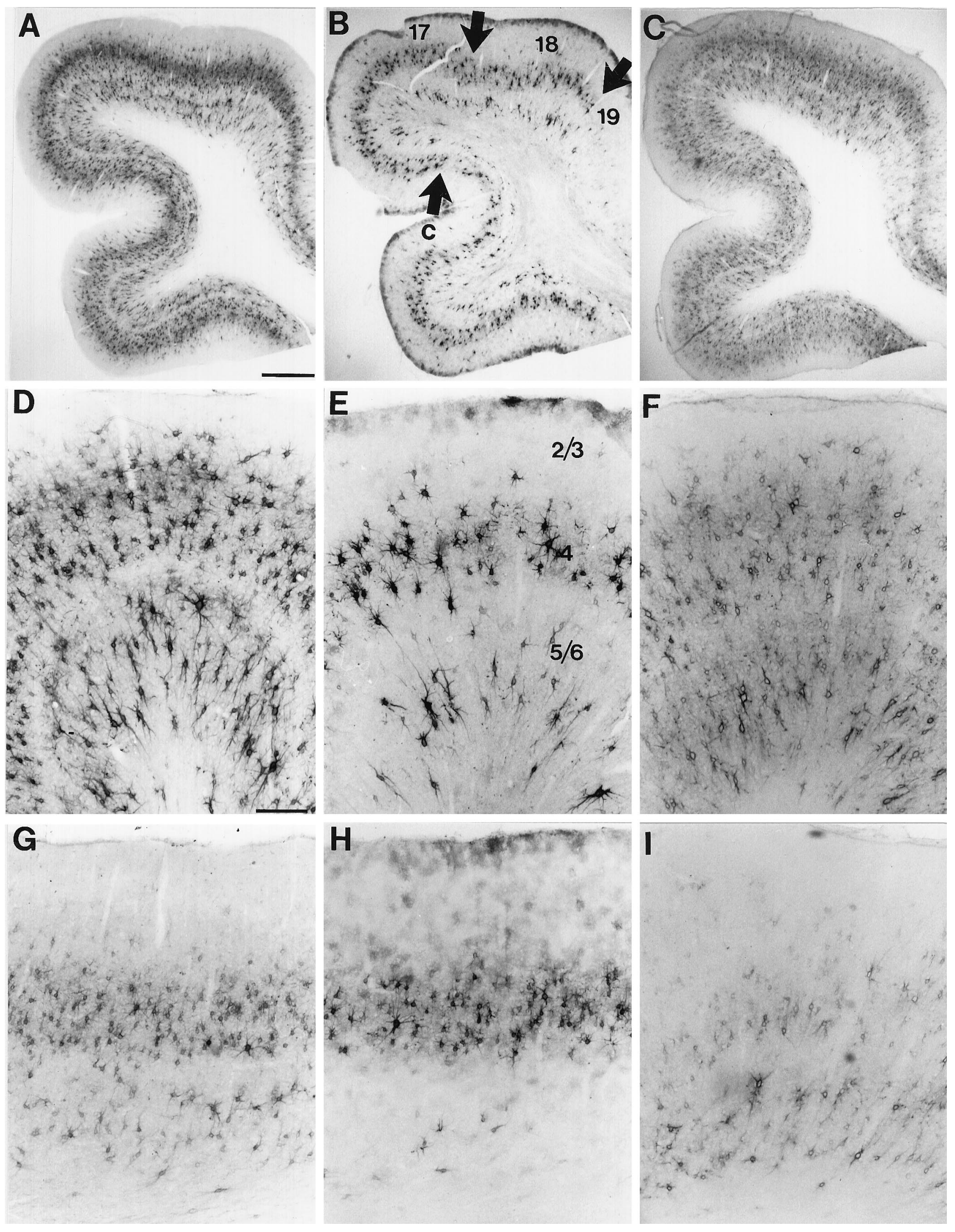


was frozen at $-20^{\circ} \mathrm{C}$ overnight. The samples were thawed, and then centrifuged, the supernatant was discarded, and the pellet was dried and then dissolved in SDS-PAGE gel loading buffer and analyzed by Western blotting.

Immunocytochemistry. Frozen sections of cat visual cortex (from animals perfused with $4 \%$ sodium phosphate-buffered paraformaldehyde while under deep anesthesia) were incubated overnight in primary antibody with $2 \%$ Triton $\mathrm{X}-100$, rinsed in phosphate buffer, and incubated in horseradish peroxidase-conjugated goat anti-mouse secondary antibody (Cappel, West Chester, PA) diluted in DMEM with 5\% fetal calf serum (FCS) and 2\% Triton X-100 for $2 \mathrm{hr}$. Sections were rinsed in phosphate buffer and reacted with $0.03 \%$ diaminobenzidine (Sigma) and $0.003 \%$ hydrogen peroxide.

For double-labeling experiments, sections were incubated overnight in either Cat-301 (an IgG) or Cat-315 (an IgM), followed by $2 \mathrm{hr}$ in fluorescein isothiocyanate-conjugated goat anti-mouse IgG (for Cat-301) or IgM (for Cat-315) secondary antibody (Southern Biotechnology Associates, Birmingham, AL). Sections were rinsed extensively in phosphate buffer and then incubated overnight in either Cat-315 or Cat-316 (both IgMs), followed by a $2 \mathrm{hr}$ incubation with Texas Red-conjugated goat anti-mouse IgM (Southern Biotechnology Associates) secondary antibody. Control experiments showed no cross-reactivity between the subclass-specific secondary antibodies and the inappropriate first antibodies. The order of primary antibody incubation did not alter the results.

Western blot analysis. Samples were combined with gel loading buffer (20 mM Tris-Cl, pH 6.8, 3\% SDS, $10 \%$ glycerol, $0.01 \%$ bromphenol blue) and $\beta$-mercaptoethanol, boiled for $5 \mathrm{~min}$, and electrophoresed on $3-8 \%$ acrylamide gradient gels in $50 \mathrm{~mm}$ Tris base, $0.38 \mathrm{M}$ glycine, and $0.2 \%$ SDS. Proteins were electrophoretically transferred to nitrocellulose overnight at $100 \mathrm{~mA}$ in $25 \mathrm{~mm}$ Tris, $0.192 \mathrm{M}$ glycine, $0.1 \%$ SDS, and $20 \%$ methanol. Blots were blocked in $5 \%$ nonfat dry milk in TBS for $1 \mathrm{hr}$, washed, and incubated with primary antibody containing $0.5 \%$ Triton X-100 overnight. Blots were washed, incubated with alkaline phosphatase-conjugated goat anti-mouse IgG secondary antibody (Promega, Madison, WI) for Cat-301, 0S, 4S, or anti-neurofilament $160 \mathrm{kDa}$ and anti-IgM secondary antibody (Cappel) for Cat-304, Cat-315, Cat-316, $6 \mathrm{~S}$, and VC1.1, which recognizes the N-linked HNK-1 carbohydrate epitope (Naegele and Barnstable, 1991; a generous gift from Colin Barnstable, Yale University) (diluted in DMEM plus 5\% FCS and $0.5 \%$ Triton X-100) for $2 \mathrm{hr}$. Immunoreactive bands were visualized with nitro-blue tetrazolium and 5-bromo-4-chloro-indolyl phosphate (Sigma).

Immunoprecipitation. Cat-301 (an IgG), Cat-315, or Cat-316 (both IgMs) were adsorbed to goat anti-mouse $\operatorname{IgG}$ or $\operatorname{IgM}$ agarose beads (Sigma) by mixing overnight at $4^{\circ} \mathrm{C}$. Beads were washed and then mixed with guanidine extracts of cat visual cortex overnight at $4^{\circ} \mathrm{C}$. Antigens were eluted by boiling in SDS-PAGE sample buffer with $\beta$-mercaptoethanol.

Tissue. Tissue from normal and dark-reared cats was generously provided by Drs. Nigel Daw and Sylvia Reid (Yale University) and Dr. Donald Mitchell (Dalhousie University).

Cell counts. Cells were counted as described in Kind et al. (1995). Briefly, sections of the visual cortex from 1-year-old cats, reared from birth either in complete darkness or in a normal visual environment, were reacted with Cat-301, Cat-315, or Cat-316 (as above), and near adjacent sections were stained with cresyl violet. Counts of antibody-positive cells were made from noncounterstained sections, because the counterstaining masks weakly antibody-positive cells. Cortical layers were considered as supragranular (layers 2 and 3), granular (layer 4), and infragranular (layers 5 and 6). Laminar boundaries were determined from adjacent
Nissl-stained sections, as well as by the distribution of pyramidal neurons labeled by Cat-301 or Cat-316. Counts of antibody-positive cells were normalized against neuronal density, as determined from near adjacent cresyl violet-stained sections. Antibody-positive neurons were counted in two or three sections separated by at least $120 \mu \mathrm{m}$ in the rostral-caudal dimension. In each section, the number of immunoreactive neurons in three fields of view were counted per layer at a magnification of $500 \times$ (field of view diameter $=0.35 \mathrm{~mm}$ ). Counts of cresyl violet-stained neurons were made from two sections separated by at least $120 \mu \mathrm{m}$; for these sections, two fields of view were counted per layer at a magnification of $1250 \times$ (field of view diameter $=0.14 \mathrm{~mm}$ ). The number of immunoreactive neurons per unit volume was normalized to the total number of neurons per unit volume to give the percentage of neurons labeled in each layer under each condition. A comparison of these density measures was then made between the two conditions for each layer to arrive at the relative change in density of antibody-stained neurons.

\section{RESULTS}

\section{Monoclonal antibodies Cat-315 and Cat-316, like Cat-301, recognize high molecular weight CSPGs}

Monoclonal antibodies Cat-315 and Cat-316 were produced using a strategy designed to generate antibodies that recognize high molecular weight, neuronal cell-surface-associated proteoglycans. Antibodies were first screened on Western blots of cat brain homogenate. Those that recognized high molecular weight antigens were subsequently screened immunohistochemically for cellsurface staining patterns. This screen produced two new antibodies, Cat-315 and Cat-316, which have properties that are similar, but not identical, to monoclonal antibody Cat-301.

Both Cat-315 and Cat-316 recognized high molecular weight, polydisperse bands on Western blots of guanidine extracts of cat visual cortex (Fig. 1). These bands co-migrated with the Cat-301 antigen, which was shown previously to be a $680 \mathrm{kDa}$ CSPG (Zaremba et al., 1989). To determine whether Cat-315 and Cat316 also recognized CSPGs, samples were subjected to enzymatic digestion before Western blot analysis. Removal of the chondroitin sulfate glycosaminoglycan side chains produced a shift in mobility of the Cat-315 antigen from $680 \mathrm{kDa}$ to $580 \mathrm{kDa}$. The digested Cat-315 antigen co-migrated with the digested Cat-301 antigen; this shift in mobility was observed after digestion with bovine testicular hyaluronidase (Fig. 1) and chondroitinase ABC (data not shown), indicating that the Cat-315 antigen is a CSPG. Digestion of the Cat-316 antigen resulted in a loss of immunoreactivity, suggesting that the Cat-316 epitope is likely to be a chondroitin sulfate glycosaminoglycan. To determine definitively whether Cat-316 recognizes a CSPG, Cat-316 immunoprecipitates were digested with chondroitinase $\mathrm{ABC}$ (or testicular hyaluronidase) and then Western-blotted with anti-0S, which recognizes the carbohydrate stub that remains after enzymatic removal of chondroitin sulfate glycosaminoglycan chains from unsulfated CSPGs (Fig. 1, lane 7). The digested Cat-316 immunoprecipitate mi-

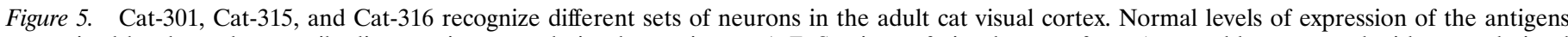

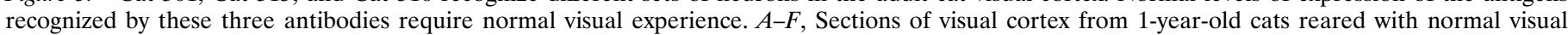

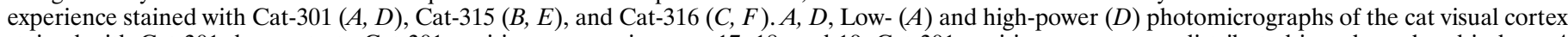

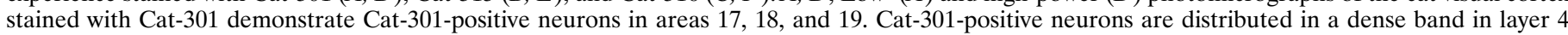

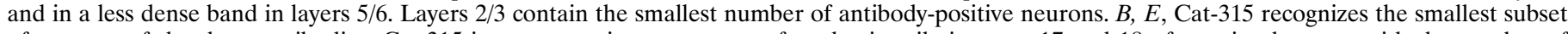

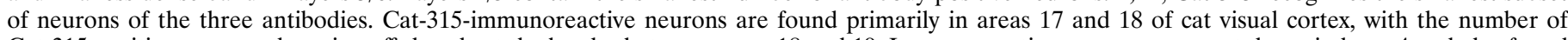

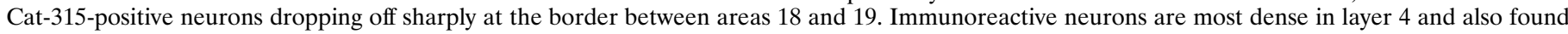

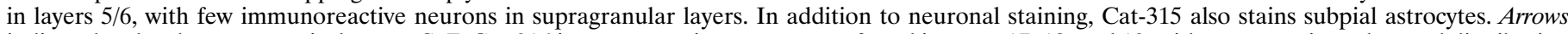

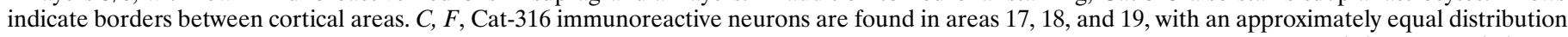

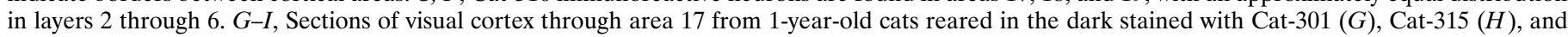

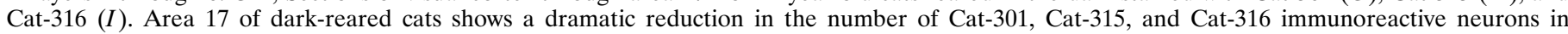

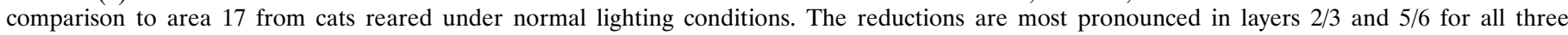
antibodies. $c$, Cingulate cortex. Scale bars: $A-C, 1 \mathrm{~mm} ; D-I, 200 \mu \mathrm{m}$. 
grated to $\sim 580 \mathrm{kDa}$ and showed immunoreactivity for anti-0S, demonstrating that the Cat-316 antigen is also a CSPG and that the Cat-316 epitope is carbohydrate. The $116 \mathrm{kDa}$ band stains with secondary antibody alone and thus represents immunoglobulin. The polydisperse appearance of the immunoreactive bands on Western blots even after glycosaminoglycan removal may be attributable to proteolysis or may reflect further heterogeneity within this high molecular weight family of CSPGs. The antigen recognized by antibodies to neurofilament showed no shift in mobility after exposure to either testicular hyaluronidase or chondroitinase, indicating that the shift in molecular weight seen for Cat-301, Cat-315, and the Cat-316 immunoprecipitate is attributable to enzymatic removal of glycosaminoglycan chains, rather than to nonspecific protease activity.

Immunoreactivity for both Cat-301 and Cat-315 was retained, whereas immunoreactivity for VC1.1 (an N-linked carbohydrate epitope) was eliminated after digestion with $N$-glycosidase F, an enzyme that cleaves $\mathrm{N}$-linked carbohydrates (Tarentino et al., 1985) (Fig. 2A). Cat-301 and Cat-315 immunoreactivities are also retained after chemical deglycosylation with TFMS, whereas immunoreactivity for Cat-316 (an O-linked, chondroitin sulfate epitope) was eliminated (Fig. $2 B$ ). With the exception of some keratan sulfates, glycosaminoglycans are O-linked substitutions (Hardingham and Fosang, 1992). Together, these data show that Cat-315 and Cat-316, like Cat-301, recognize CSPGs expressed in cat visual cortex and, furthermore, that the epitopes recognized by Cat-301 and Cat-315 are likely to be on the protein core of the CSPGs.

\section{Cat-301, Cat-315, and Cat-316 recognize related yet distinct sets of proteoglycans}

To determine the relationship among the CSPGs recognized by Cat-301, Cat-315, and Cat-316, guanidine extracts of cat visual cortex were immunoprecipitated with goat anti-mouse IgG or IgM agarose beads preadsorbed to Cat-301 (an IgG), Cat-315 (an IgM), and Cat-316 (an IgM). Immunoprecipitated antigens were subjected to Western blot analysis and probed with Cat-301, Cat-315, and Cat-316 (Fig. $3 A$ ).

Antigens immunoprecipitated by each of the three antibodies showed immunoreactivity for the other two antibodies, as well as for the precipitating antibody. Cat-301 immunoprecipitates were recognized by Cat-315 and Cat-316; Cat-315 immunoprecipitates were recognized by Cat-301 and Cat-316; and Cat-316 immunoprecipitates were recognized by Cat-315 and Cat-301 (Fig. $3 A$ ). The intensity of staining for each antibody varied, depending on the precipitating antibody; each antibody showed the strongest immunoreactivity to antigens precipitated by itself. In control experiments, a nonrelated primary antibody [Cat-307 (Kind et al., 1994), an IgM; anti-NF $160 \mathrm{kDa}$, an IgG] did not precipitate immunoreactive antigens (data not shown), demonstrating that the immunoreactive precipitates seen on the Western blots were not the result of nonspecific antibody binding. Identical results were obtained when immunoprecipitations were carried out in the presence of SDS (Sano et al., 1993), indicating that the observed co-precipitations were not caused by intermolecular associations. This experiment demonstrated that there are brain CSPGs that carry epitopes for more than one of the three antibodies used here (Fig. 3E, $(A))$.

To explore the possible existence of CSPGs that express epitopes for all three antibodies, Cat-316 was used to immunoprecipitate CSPGs, and these Cat-316-expressing CSPGs were subsequently digested with chondroitinase $\mathrm{ABC}$ (to remove the CSPG from the immunobeads). The eluted material was immunoprecipitated with Cat-301 and then Western-blotted with Cat301 and Cat-315 (Fig. 3B). The material immunoprecipitated by Cat-316 and then by Cat-301 retained immunoreactivity for Cat315, demonstrating that there are brain CSPGs that carry epitopes recognized by all three antibodies (Fig. $3 E,(B)$ ).

These co-precipitation experiments suggested that all three antibodies can recognize epitopes on a single proteoglycan. To test whether there are brain CSPGs that do not express all three epitopes, an exhaustive immunoprecipitation analysis was performed (Fig. 3C). An aliquot of guanidine-extracted cat visual cortex was subjected to six successive rounds of immunoprecipitation with Cat-316 to remove all immunoprecipitatable Cat-316 antigen from the extract. After depletion of Cat-316, the extract was immunoprecipitated with Cat-315. This Cat-315 immunoprecipitate showed substantial amounts of Cat-315 immunoreactivity, demonstrating that not all brain CSPGs that have epitopes for Cat-315 also have epitopes for Cat-316. The material that was depleted of Cat-316 also showed immunoreactivity for Cat-301 (data not shown). Parallel experiments, in which the extract was first depleted of Cat-315 and then tested for the presence of Cat-316, showed further that not all Cat-316-positive CSPGs carry Cat-315 epitopes. This immunodepletion analysis was also performed for Cat-301 versus Cat-315, and for Cat-301 versus Cat-316, with identical results. That is, no matter which antibody was used to initially deplete the extract, immunoreactivity always remained for both of the other two antibodies. In each case, the final immunoprecipitates (the material shown in Fig. 3C, lanes 7 and 14) never contained immunoreactivity for the antibody used for the initial immunodepletion. These exhaustive immunodepletion analyses demonstrate the existence of brain CSPGs that carry epitopes for only two of the three antibodies (Fig. 3E, (C)).

In addition, there are brain CSPGs that carry only one of the three epitopes. This was demonstrated by immunodepleting extracts using first one and then a second antibody. After this double depletion, immunoreactivity was retained for the third antibody (Fig. 3D,E, (D)). In sum, the three antibodies used here define a complex family of CSPGs, some with epitopes for only one of the antibodies, some with epitopes for more than one antibody, and some with epitopes for all three antibodies. Together, the coimmunoprecipitation and immunodepletion results demonstrate that the Cat-301, Cat-315, and Cat-316 antigens represent overlapping yet distinct sets of proteoglycans.

\section{Cat-301, Cat-315, and Cat-316 immunoreactivity decorates the surfaces of neurons in a lattice-like pattern characteristic of perineuronal nets}

Immunohistochemistry on tissue sections of cat visual cortex demonstrated that the antigens recognized by Cat-301, Cat-315, and Cat-316 are distributed over the surface of neurons (Fig. 4). The staining of neuronal cell bodies and proximal dendrites was not homogeneous but was interrupted by small holes or fenestrae. This is the same pattern of staining seen with Cat-301, where immunoelectron microscopy has demonstrated that the "holes" in the surface staining represent the sites of synaptic contacts (Hockfield and McKay, 1983; Zaremba et al., 1989). The distribution of the Cat-301, Cat-315, and Cat-316 CSPGs over the neuronal cell body and proximal dendrites is similar to that of the "perineuronal 
nets" first described by Golgi (1893) and Ramon y Cajal (1897) (for review, see Celio and Blumcke, 1994).

\section{Distinct sets of neurons are recognized by Cat-301, Cat-315, and Cat-316 in cat visual cortex}

The biochemical demonstration of overlapping subsets of CSPGs next led us to ask whether the CSPGs recognized by Cat-301, Cat-315, and Cat-316 would be expressed on nonidentical subsets of neurons. Cat-301, Cat-315, and Cat-316 displayed distinct patterns of immunoreactivity in cat visual cortex (Fig. 5). Cat-315 recognized the smallest set of neurons (Fig. $5 B, E$ ), largely limited to a major band in layer 4 and a second, less dense band in layers $5 / 6$. A small number of neurons in layers $2 / 3$ were immunoreactive for Cat-315. Only nonpyramidal neurons were found to be immunoreactive for Cat-315. Cat-315-positive neurons were most prevalent in areas 17 and 18, with the number of Cat-315 immunoreactive neurons dropping off sharply at the border between areas 18 and 19. In addition to neuronal immunoreactivity, Cat-315 also showed some staining of subpial astrocytes.

Cat-316-positive neurons were also observed throughout areas 17 and 18 (Fig. 5C,F) and were present at a higher density than Cat-315-positive neurons. Unlike the distribution of neurons immunoreactive for the other two antibodies, which showed a predominance in particular cortical layers, Cat-316-positive neurons were distributed more equally in layers 2-6. Although the majority of Cat-316-positive neurons was nonpyramidal in morphology, a number of stained pyramidal neurons were also observed. Unlike Cat-315, Cat-316 labeling continued beyond areas 17 and 18 and into adjacent cortical areas.

As reported previously (Hockfield et al., 1983; Guimaraes et al., 1990), Cat-301-positive neurons were found in areas 17 and 18 and continued into the adjacent cortical areas (Fig. 5A,D). The highest density of antibody-positive neurons was found in layer 4 , with neurons also labeled in superficial and deep layers. Like Cat-316 and in contrast to Cat-315, Cat-301 labeled pyramidal as well as nonpyramidal neurons in the cat visual cortex.

Double-labeling experiments were performed to determine whether the population of neurons recognized by each of the antibodies was independent of the other two. In experiments using Cat-315 and Cat-301 (Fig. 6 $A, B$ ), only two different populations of cat visual cortical neurons were observed: those labeled by both antibodies (Cat-301+/Cat-315+) and those labeled by Cat-301 but negative for Cat-315 (Cat-301+/Cat315-). All Cat-315-positive neurons were also Cat-301positive, indicating that the Cat-315-positive neurons represent a subset of the Cat-301-positive neurons in cat visual cortex. The Cat-301-/Cat-315+ subpopulation of antigens defined biochemically can probably be accounted for by the subpial astrocytes, which stain with Cat-315 but not Cat-301. In several areas of the brain outside of the visual cortex, however, we have observed Cat-315-positive, Cat-301-negative neurons (data not shown).

Double-labeling experiments using Cat-315 and Cat-316 (Fig. $6 C, D)$ showed all three of the possible populations of immunoreactive neurons: Cat-315+/Cat-316-, Cat-315+/Cat-316+, and Cat-315-/Cat-316+. Layers $2 / 3$ contained a large population of neurons labeled by Cat-316 but negative for Cat-315, and a smaller population of double-labeled neurons. Layer 4 contained predominantly double-labeled cells, with a population of Cat$315+/$ Cat-316 - neurons found in the lower part of the layer. As in layers $2 / 3$, in layers $5 / 6$ many neurons were recognized only by
Cat-316, but a substantial number of double-labeled neurons were also seen.

There were also three classes of Cat-301/Cat-316 neurons (Fig. $6 E-G$ ). Many of the neurons in the top part of layers $2 / 3$ that were immunoreactive for Cat-316 were not recognized by Cat-301 (Fig. 6G,H). In addition, there was a substantial number of double-labeled neurons in the lower part of layers $2 / 3$. Almost all neurons in layer 4 were double-labeled, with a few Cat-301+/Cat-316- neurons in the deep part of layer 4. In layers 5/6, almost all labeled neurons were positive for both of these antibodies.

\section{Expression of Cat-301, Cat-315, and Cat-316 antigens in cat visual cortex requires normal visual experience}

We have shown previously that visual deprivation during the early postnatal period reduces the number of Cat-301-positive neurons in the cat visual cortex (Guimaraes, 1990). To determine whether the immunohistochemical staining patterns of the two new antibodies were similarly regulated by visual experience, we examined visual cortex from cats that had been dark-reared from birth to $\sim 1$ year of age (Fig. $5 G-I$ ). The number of Cat-315 and Cat-316 immunoreactive neurons was reduced in the visual cortex of dark-reared animals compared with age-matched control animals. The most marked reductions in immunoreactivity for all three antibodies were seen in layers $2 / 3$ and $5 / 6$.

Cell counts were made of sections from normal and dark-reared animals and the density of antibody-positive neurons under the two conditions was compared for each antibody (Table 1). For all three antibodies, dark-rearing produced a substantial decrease in antibody-stained neurons in layers $2 / 3$ and $5 / 6$. A less dramatic reduction in antibody-stained neurons was observed in layer 4 for Cat-301 and Cat-316, whereas a small apparent increase in antibody-stained neurons was detected in layer 4 for Cat-315 (also see Fig. $5 H$ ).

Double-labeling experiments on tissue sections confirmed that the expression of more than one cell surface CSPG was affected by dark-rearing. For example, the population of Cat-316 neurons normally seen in the upper part of layers $2 / 3$ was absent in the dark-reared animals, so that all of the labeled neurons in layers 2/3 were double-labeled for Cat-301 and Cat-316 after darkrearing. In layer 4 , there were more neurons that were labeled by Cat-301 and not by Cat-316 than seen in normally reared animals. In addition, in layer 4, although there was a reduction in the number of both Cat-301- and Cat-316-positive neurons, the number of Cat-315-positive neurons did not decline.

\section{DISCUSSION}

Cat-301, Cat-315, and Cat-316 recognize nonidentical sets of proteoglycans expressed on different subsets of neurons

5In the present study, we have used monoclonal antibodies Cat301, Cat-315, and Cat-316 to identify a family of high molecular weight cell-surface CSPGs in the cat visual cortex. Although they co-migrate on Western blots, the CSPGs recognized by Cat-315 and Cat-316 are not identical to the Cat-301 CSPG or to one another, revealing a high level of complexity within this family. Exhaustive immunodepletions demonstrate distinct CSPGs with epitopes for only Cat-301, Cat-315, or Cat-316, whereas coimmunoprecipitations demonstrate CSPGs that carry epitopes for more than one, and as many as three, of these antibodies. This 

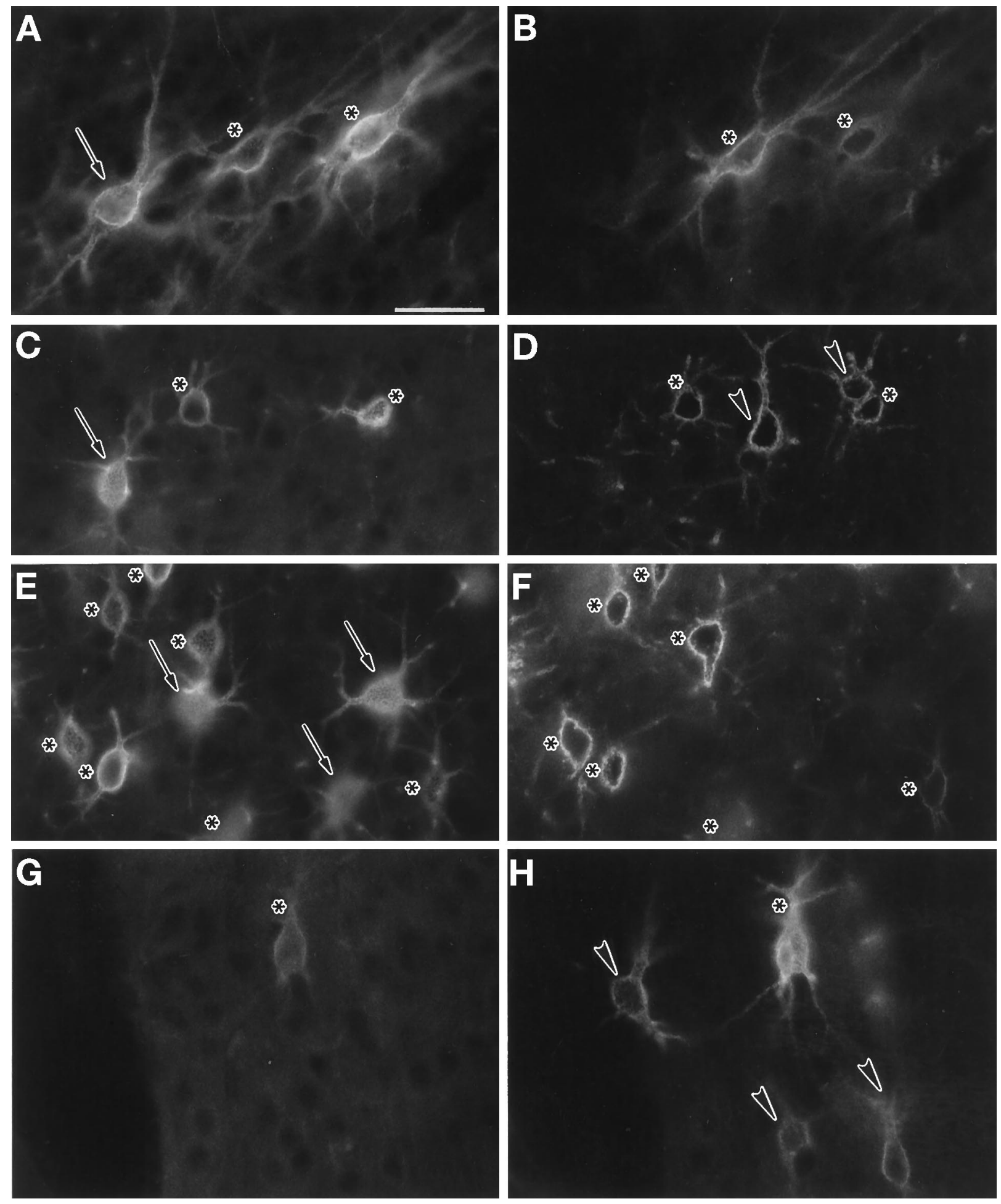

Figure 6. Cat-301, Cat-315, and Cat-316 recognize overlapping but distinct subsets of neurons. $A$, $B$, Double-label immunofluorescence with Cat-301 ( $A$ ) and Cat-315 (B) demonstrates two sets of immunoreactive neurons in cat visual cortex: neurons positive for both Cat-301 and Cat-315 (asterisks) and neurons positive for Cat-301 but negative for Cat-315 (arrows). Cat-315-positive neurons represent a subset of the Cat-301-positive neurons in cat visual cortex. $C$, $D$, Double-label immunofluorescence with Cat-315 $(C)$ and Cat-316 (D) shows three sets of immunoreactive neurons: those positive for only Cat-315 (arrow) or only Cat-316 (arrowheads) and those positive for both Cat-315 and Cat-316 (asterisks). E-H, Double-label immunofluorescence with Cat-301 $(E, G)$ and Cat-316 $(F, H)$ also reveals three sets of neurons: Cat-301+/Cat-316- (arrows), Cat-301+/Cat-316+ (asterisks), and Cat-301-/Cat-316+ (arrowheads). Scale bar, 50 $\mu \mathrm{m}$.

analysis indicates the existence of as many as seven immunologically distinct brain CSPGs (Fig. 3). Indeed, the polydispersity remaining after glycosaminoglycan removal indicates that substantial additional heterogeneity may exist.
Our biochemical analyses demonstrating heterogeneity among brain CSPGs are complemented and extended by the immunohistochemical analysis of CSPG expression by neuronal subsets. Each of the three antibodies studied here recognizes a 
Table 1. Dark-rearing reduces CSPG expression on neurons in the cat visual cortex

\begin{tabular}{|c|c|c|c|c|c|}
\hline & \multicolumn{2}{|c|}{$\begin{array}{l}\text { Number of labeled } \\
\text { neurons }^{a}\end{array}$} & \multicolumn{2}{|c|}{$\begin{array}{l}\text { Density of labeled } \\
\text { neurons }^{b}\end{array}$} & \multirow[b]{2}{*}{$\begin{array}{l}\mathrm{DR} / \text { normal }^{\mathrm{c}} \\
(\%)\end{array}$} \\
\hline & Normal & DR & $\begin{array}{l}\text { Normal } \\
(\%)\end{array}$ & $\begin{array}{l}\mathrm{DR} \\
(\%)\end{array}$ & \\
\hline \multicolumn{6}{|l|}{ Layers $2 / 3$} \\
\hline Cat-301 & 18.1 & 7.5 & 18.6 & 4.0 & 21.5 \\
\hline Cat-315 & 3.2 & 0.3 & 3.3 & 0.18 & 5.4 \\
\hline Cat-316 & 15.8 & 7.8 & 16.2 & 4.2 & 25.9 \\
\hline \multicolumn{6}{|l|}{ Layer 4} \\
\hline Cat-301 & 24.8 & 39.0 & 25.5 & 24.9 & 97.6 \\
\hline Cat-315 & 12.3 & 23.7 & 12.6 & 15.1 & 120.0 \\
\hline Cat-316 & 17.5 & 19.2 & 18.0 & 12.2 & 67.8 \\
\hline \multicolumn{6}{|l|}{ Layers 5/6 } \\
\hline Cat-301 & 15.8 & 11.2 & 17.5 & 5.9 & 33.7 \\
\hline Cat-315 & 6.0 & 3.9 & 6.6 & 2.0 & 30.3 \\
\hline Cat-316 & 10.0 & 6.2 & 11.1 & 3.2 & 28.8 \\
\hline
\end{tabular}

DR, Dark-reared.

${ }^{a}$ The number of cells per field of view, which represents $3.85 \times 10^{-3} \mathrm{~mm}^{3}$.

${ }^{b}$ The ratio of antibody-positive neurons per unit volume to total neurons per unit volume, expressed as percentage.

${ }^{c}$ The ratio of $\%$ labeled neurons in dark-reared versus normal animals, expressed as percentage.

distinct set of neurons in cat visual cortex. In double-labeling experiments using any pair of antibodies, both single- and double-labeled neurons are found. Neurons recognized by only one antibody must carry cell-surface CSPGs recognized by that antibody; however, double-labeled neurons may express either two different CSPGs, each recognized by one antibody only or, instead, a single CSPG that bears epitopes for two different antibodies. Although our biochemical data show that the latter alternative is likely to occur, epitope mapping and additional structural analysis will be required to discriminate between these possibilities. The most critical observation for the present analysis, however, is that there are neurons that express CSPGs recognized by only one member of each antibody pair. Furthermore, in other areas of the CNS outside of visual cortex, these three antibodies label completely nonoverlapping sets of neurons. These results show that antigenically distinct CSPGs are carried on the surfaces of different sets of neurons.

Previous work has demonstrated that brain proteoglycans exhibit heterogeneity in both core protein and glycosaminoglycan composition and that different sets of neurons can express proteoglycans that differ in their glycosylation pattern. Fujita and colleagues (Fujita et al., 1989; Sano et al., 1993) described two monoclonal antibodies to glycosaminoglycan epitopes that recognize CSPGs that co-migrate on Western blots but that associate with the surfaces of different sets of neurons. Bertolotto et al. (1990, 1991, 1996) described the distribution of CSPGs in adult brain using monoclonal antibodies that recognize the unsulfated, 4-sulfated, or 6-sulfated disaccharides that are exposed on CSPGs after chondroitinase digestion (Caterson et al., 1985). Each of these antibodies also recognizes a distinct set of neurons, which in cat visual cortex is different from the sets recognized by Cat-301 (Hockfield et al., 1990), Cat-315, or Cat-316 (unpublished observations). Together, these observations indicate that brain cell-surface CSPGs are distinguished by their carbohydrate modifications.
CSPG core proteins have also been shown to be diverse on the basis of differences in molecular weight on SDS-PAGE (Oohira et al., 1988; Gowda et al., 1989; Herndon and Lander, 1990; Hockfield et al., 1990). The epitopes for antibodies Cat-301 and Cat-315 are most likely core protein and not carbohydrate, as indicated by the retention of immunoreactivity after enzymatic or chemical deglycosylation. It is possible, however, that unusual carbohydrate epitopes resistant to these treatments could represent the epitopes recognized by Cat-301 and Cat-315. This issue will only be fully resolved once the genes for these proteins are identified and characterized. The CSPGs recognized by Cat-301 and Cat-315 have the same apparent molecular mass but are immunochemically and immunohistochemically different from one another. Our present data suggest strongly that neuronal cell-surface CSPGs can differ in their protein cores as well as in their carbohydrate modifications. Importantly, they also suggest that protein cores can differ even among CSPGs that have identical apparent molecular weights.

\section{Cat-301, Cat-315, and Cat-316 cell-surface immunoreactivity is regulated by neuronal activity}

The normal development of the cat visual cortex requires normal visual experience during the circumscribed period early in life called the critical period. Abnormal visual experience during the first three postnatal months can lead to dramatic changes in the response properties, connectivity, and molecular phenotype of neurons in central visual areas (Sherman and Spear, 1982; Sur et al., 1988; Guimaraes et al., 1990).

Rearing animals in complete darkness extends the critical period during which neurons are susceptible to monocular deprivation (Cynader and Mitchell, 1980; Mower et al., 1985; Mower, 1991a) and has been used extensively to identify molecules that are candidates for involvement in plasticity. For example, darkrearing delays the age-dependent decline in NMDA receptor contribution to visual responses (Fox et al., 1991, 1992; Czepita et al., 1994), inhibits the transient increase in phosphoinositide turnover resulting from metabotropic glutamate receptor activation (Dudek and Bear, 1989), prevents the age-dependent decline in levels of growth-associated protein GAP-43 messenger RNA (Mower and Rosen, 1993), and alters the state of phosphorylation of the microtubule-associated protein MAP-2 (Aoki and Siekevitz, 1985).

We showed previously that dark-rearing also reduces the expression of the Cat-301 proteoglycan in the visual cortex, which is normally expressed at the close of the critical period (Guimaraes et al., 1990). Therefore, the apparent physiological immaturity of dark-reared visual cortex is mirrored by immaturity in the expression of at least one cell-surface CSPG. Here, we have asked whether the activity-dependent decrease in Cat-301 immunoreactivity was specific to the Cat-301 proteoglycan, or if other cell surface CSPGs might be similarly affected by dark-rearing. As with Cat-301, dark-rearing from birth also results in a decrease in cell-surface immunoreactivity for Cat-315 and Cat-316 in cat visual cortex. Our analysis demonstrates that the expression of more than one of the CSPGs identified here requires normal patterns of neuronal activity. Unfortunately, it is not possible with the reagents currently available to determine whether the expression of all seven immunologically distinct CSPGs is similarly regulated.

The reduction in Cat-315 and Cat-316 immunoreactivity 
after dark-rearing is most pronounced outside of layer 4, as we reported previously for Cat-301. Other studies of dark-reared cats also show the most marked effects in extragranular layers. Dark-rearing produces an elevation in 5HT1 receptor expression primarily in supra- and infragranular layers (Mower, 1991b). Dark-rearing also retards the maturation of astrocytes in layers 2/3 and 5/6, with little change in layer 4 (Muller, 1990). Furthermore, in cats dark-reared to 4 months of age, subsequent monocular eyelid suture does not change the binocularity of neurons in layer 4 , whereas neurons outside of layer 4 come to be dominated by the open eye (Mower and Christen, 1985). These studies all indicate that dark-rearing can delay the normal time course of the critical period in visual cortex outside of layer 4; however, dark-rearing attenuates the agedependent downregulation in the NMDA receptor contribution to visual responses in all layers of cortex (Czepita et al., 1994), indicating that dark-rearing can also alter some aspects of the development of layer 4 .

Together, the results presented here demonstrate that the Cat301/315/316 family of neuronal cell-surface, high molecular weight CSPGs is complex. Different CSPGs are expressed by different sets of neurons, and their expression can be regulated by activity. Activity-dependent expression of the Cat-301 CSPG has also been observed in the cat lateral geniculate nucleus (Sur et al., 1988) and rodent spinal cord (Kalb and Hockfield, 1988, 1990a,b, 1992), raising the possibility that the regulation of CSPG expression by activity may be a general phenomenon throughout the CNS. In addition, the heterogeneity within this group of cell-surface molecules and the association of particular CSPGs with specific subsets of neurons may reflect an exquisite degree of regulation of the extracellular microenvironment surrounding each neuron within the brain.

\section{REFERENCES}

Aoki C, Siekevitz P (1985) Ontogenetic changes in the cyclic adenosine $3^{\prime}, 5^{\prime}$-monophosphate-stimulatable phosphorylation of cat visual cortex proteins, particularly of microtubule-associated protein 2 (MAP 2): effects of normal and dark-rearing and of the exposure to light. J Neurosci 5:2465-2483.

Bertolotto A, Rocca G, Schiffer D (1990) Chondroitin 4-sulfate proteoglycan forms an extracellular network in human and rat central nervous system. J Neurol Sci 100:113-123.

Bertolotto A, Rocca G, Canavese G, Migheli A, Schiffer D (1991) Chondroitin sulfate proteoglycan surrounds a subset of human and rat CNS neurons. J Neurosci Res 29:225-234.

Bertolotto A, Manzardo E, Guglielmone R (1996) Immunohistochemical mapping of perineuronal nets containing chondroitin unsulfate proteoglycan in the rat central nervous system. Cell Tissue Res 283:283-295.

Caterson B, Christner JE, Baker JR, Couchman JR (1985) Production and characterization of monoclonal antibodies directed against connective tissue proteoglycans. Fed Proc 44:386-393.

Celio MR, Blumcke I (1994) Perineuronal nets: a specialized form of extracellular matrix in the adult nervous system. Brain Res Rev 19:128-145.

Cynader M, Mitchell DE (1980) Prolonged sensitivity to monocular deprivation in dark-reared cats. J Neurophysiol 43:1026-1040.

Czepita D, Reid SNM, Daw NW (1994) Effect of longer periods of dark-rearing on NMDA receptors in cat visual cortex. J Neurophysiol 72:1220-1226.

DeYoe EA, Hockfield S, Garren H, Van Essen D (1990) Antibody labeling of functional subdivisions in visual cortex: Cat-301 in V1, V2, V3 and MT of the Macaque monkey. Vis Neurosci 5:67-81.

Dudek SM, Bear MF (1989) A biochemical correlate of the critical period for synaptic modification in the visual cortex. Science 246:673-675.
Fox K, Daw N Sato H, Czepita D (1991) Dark-rearing delays the loss of NMDA-receptor function in kitten visual cortex. Nature 350:342-344.

Fox K, Daw N, Sato H, Czepita D (1992) The effect of visual experience on development of NMDA receptor synaptic transmission in kitten visual cortex. J Neurosci 12:2672-2684.

Fujita SC, Toda Y, Murakami F, Hayashi M, Matsamura M (1989) Glycosaminoglycan-related epitopes surround different subsets of mammalian central nervous system neurons. Neurosci Res 7:117-130.

Golgi C (1893) Intorno all-origine del quarto nervo cerebrale e una questione isto-fisiologica che a questo argomento si collega. Rendiconti della Reale Accademia dei Lincei (21 maggio) 2:443-450.

Gowda DC, Margolis RU, Margolis RK (1989) Presence of the HNK-1 epitope on poly ( $N$-acetyllactosaminyl) oligosaccharides and identification of multiple core proteins in the chondroitin sulfate proteoglycans of brain. Biochemistry 28:4468-4474.

Guimaraes A, Zaremba S, Hockfield S (1990) Molecular and morphological changes in the cat lateral geniculate nucleus and visual cortex induced by visual deprivation are revealed by monoclonal antibodies Cat-304 and Cat-301. J Neurosci 10:3014-3024.

Hardingham TE, Fosang AJ (1992) Proteoglycans: many forms and many functions. FASEB J 6:861-870.

Herndon ME, Lander AD (1990) A diverse set of developmentally regulated proteoglycans is expressed in the rat central nervous system. Neuron 4:949-961.

Hockfield S, McKay RDG (1983) A surface antigen expressed by a subset of neurons in the vertebrate central nervous system. Proc Natl Acad Sci USA 80:5758-5761.

Hockfield S, McKay RD, Hendry SHC, Jones EG (1983) A surface antigen that identifies ocular dominance columns in the visual cortex and laminar features of the lateral geniculate nucleus. Cold Spring Harb Symp Quant Biol 48:877-889.

Hockfield S, Kalb RG, Zaremba S, Fryer H (1990) Expression of neural proteoglycans correlates with the acquisition of mature neuronal properties in the mammalian brain. Cold Spring Harb Symp Quant Biol 55:505-513.

Hockfield S, Carlson S, Evans C, Levitt P, Pintar J, Silberstein L (1993) Molecular probes of the nervous system: selected methods for antibody and nucleic acid probes. Cold Spring Harbor, NY: Cold Spring Harbor Laboratory.

Horvath E, Edwards AM, Bell JC, Braun PE (1989) Chemical deglycosylation on a micro-scale of membrane glycoproteins with retention of phosphoryl-protein linkages. J Neurosci Res 24:398-401.

Kalb R, Hockfield S (1988) Molecular evidence for early activitydependent development of hamster motor neurons. J Neurosci 8:2350-2360.

Kalb R, Hockfield S (1990a) Large diameter primary afferent input is required for developmental expression of a proteoglycan on the surface of motor neurons. Neuroscience 34:391-401.

Kalb RG, Hockfield S (1990b) Induction of a neuronal proteoglycan by the NMDA receptor in the developing spinal cord. Science 250:294-296.

Kalb RG, Hockfield S (1992) Activity-dependent development of spinal cord motor neurons. Brain Res Rev 17:283-289.

Kind P, Blakemore C, Fryer H, Hockfield S (1994) Identification of proteins down-regulated during the postnatal development of the cat visual cortex. Cereb Cortex 4:361-375.

Kind PC, Beaver CJ, Mitchell DE (1995) Effects of early periods of monocular deprivation and reverse lid suture on the development of Cat-301 immunoreactivity in the dorsal lateral geniculate nucleus (dLGN) of the cat. J Comp Neurol 359:523-536.

Mower GD (1991a) The effect of dark-rearing on the time course of the critical period in cat visual cortex. Dev Brain Res 58:151-158.

Mower GD (1991b) Comparison of serotonin 5-HT1 receptors and innervation in the visual cortex of normal and dark-reared cats. J Comp Neurol 312:223-230.

Mower GD, Christen WG (1985) Role of visual experience in activating critical period in cat visual cortex. J Neurophysiol 53:572-589.

Mower GD, Rosen KM (1993) Developmental and environmental changes in GAP-43 gene expression in cat visual cortex. Mol Brain Res 20:254-258.

Mower GD, Caplan CJ, Christen WG, Duffy FH (1985) Dark-rearing prolongs physiological but not anatomical plasticity of the cat visual cortex. J Comp Neurol 235:448-466. 
Muller CM (1990) Dark-rearing retards the maturation of astrocytes in restricted layers of cat visual cortex. Glia 3:487-494.

Naegele JR, Barnstable CJ (1991) A carbohydrate epitope defined by monoclonal antibody VC1.1 is found on N-CAM and other cell adhesion molecules. Brain Res 559:118-129.

Oohira A, Matsui F, Matsuda M, Takida Y, Kuboki Y (1988) Occurrence of three distinct molecular species of chondroitin sulfate proteoglycan in the developing rat brain. J Biol Chem 263: 10240-10246.

Ramon y Cajal S (1897) La red superficial de las celulas nerviosas centrales. Rev trimest miocrografica Madrid 3:163-178.

Sano S, Kudo J, Fujita SC (1993) Different subsets of CNS neurons66 express different glycosaminoglycan epitopes on large perineuronal proteoglycans. Brain Res 630:65-74.
Sherman SM, Spear PD (1982) Organization of visual pathways in normal and visually deprived cats. Physiol Rev 62:738-855.

Sur M, Frost DO, Hockfield S (1988) Expression of a surface-associated antigen on Y-cells in the cat lateral geniculate nucleus is regulated by visual experience. J Neurosci 8:874-882.

Tarentino AL, Gomez CM, Plummer Jr TH (1985) Deglycosylation of asparagine-linked glycans by peptide:N-glycosidase F. Biochemistry 24:4665-4671.

Wight TN, Heinegard DK, Hascall VC (1991) Proteoglycans: structure and function In: Cell biology of extracellular matrix, 2nd ed (Hay ED, ed), pp 45-78. New York: Plenum.

Zaremba S, Guimaraes A, Kalb RG, Hockfield S (1989) Characterization of an activity-dependent, neuronal surface proteoglycan identified with monoclonal antibody Cat-301. Neuron 2:1207-1219. 